\title{
Effects of Library Instruction on University Students' Satisfaction with the Library: A Longitudinal Study
}

\section{Anthony Stamatoplos and Robert Mackoy}

\begin{abstract}
Consideration of satisfaction should be an important part of the evaluation of library services. Satisfaction depends, to some extent, on patron expectations of services. This study evaluated changes in student expectations following library instruction and how they were related to overall, long-term satisfaction with the library. Satisfaction appeared to be related to student perceptions of information accessibility, staff competence and helpfulness, computer usefulness and ease of use, and skill level for using libraries. The study suggests that libraries may be well served by measuring patron satisfaction and learning what variables drive satisfaction at particular libraries.
\end{abstract}

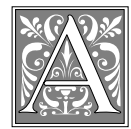

ssessment and service quality are two of the dominant themes in library research today. Over the past three years, College $\mathcal{E}$ Research Libraries has published numerous articles on each of these themes. Yet no research has appeared to date in which empirical evidence is used to address both themes simultaneously. The study reported here represents a preliminary attempt to determine the impact of a library instruction program on patrons' overall, long-term satisfaction with a large, urban university library. The ultimate goal of this research effort is to define the "drivers" of patron satisfaction at the library. As such, the goal of this study was not to measure objective changes in skill or knowledge level resulting from library instruction but, rather, to evaluate perceptual changes following instruction and then to track whether these changes are related to patron satisfaction levels with library service.

Although several studies have measured relevant variables pre- and postinstruction, none has evaluated the effect of post-instruction perceptions on longerterm patron satisfaction. Ought the effect of library instruction on patron satisfaction be judged immediately following instruction or several months later? Each is valuable, but for different reasons. Shortterm evaluations provide useful feedback for the instructor, assessment of the teaching methods, effectiveness of meeting specific library instruction objectives, and so on. Long-term evaluations can determine lasting effects of instruction, retention of information, and the effects of instruction on patron perception of, and satisfaction with, overall library service.

Anthony Stamatoplos is an Assistant Librarian at Indiana University/Purdue University-Indianapolis; e-mail: astamato@iupui.edu. Robert Mackoy is an Assistant Professor of Business at Butler University; email: mackoy@thomas.butler.edu. 
Why should library administrators care about patron satisfaction? Some think patron satisfaction is of secondary importance-that the purpose of a library is to provide information services and that evaluation of the library performance ought to be judged from that perspective alone. However, others recognize that failing to satisfy the patron is failing to serve the patron. This is not about just making patrons "feel good." There is a basic reason for focusing on patron satisfaction: Who is the best judge of whether a patron has been served well or poorly? Professional librarians may know whether they have provided accurate, timely information in response to a request. Is that enough? Clearly, accurate and timely information is a minimum requirement, but unless the patron is satisfied, in general, the service could have been better.

\section{Evaluating Satisfaction}

Researchers in the fields of consumer behavior and marketing have focused on understanding satisfaction only since the late 1970s. Satisfaction is considered to be an important topic because it is thought to be related to organizational objectives of repeat patronage and positive word of mouth. In the 1980s, the U.S. government sought to encourage and reward "quality" in U.S. organizations, most visibly through creation of the Malcolm Baldrige Award for Quality. The creators of this (and other) quality awards recognized that satisfaction plays a major role in defining what quality is. For example, satisfaction is the single most heavily weighted component on an organization's final score in evaluating Baldrige Award applications.

After the importance of satisfaction was recognized, researchers began trying to define it, measure it, and determine what causes it. ${ }^{1}$ Although numerous definitions of the term exist, most researchers would agree that satisfaction is a reaction to a patron's subjective assessment of the degree to which the organization's performance met or exceeded some standard internalized by the patron. This definition provides hints about how satisfaction should and should not be measured. First, the measure needs to be subjective: Only the patron can judge whether he or she is satisfied. Second, satisfaction should be measured on a continuum rather than on a dichotomous scale: Most people experience satisfaction in greater or lesser degrees, depending on numerous factors.

The question of what causes satisfac-

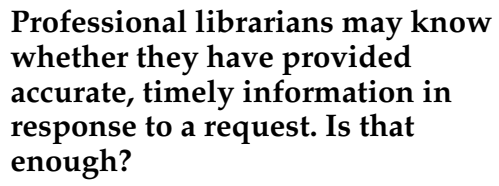

Professional librarians may know whether they have provided accurate, timely information in response to a request. Is that enough?

tion is still being investigated. ${ }^{2}$ One thing that is clear from the above definition is that satisfaction depends to a certain extent on the standard internalized by the patron and on the perceived level of performance of the organization. The standard that has been most widely tested and used has been predictive expectationsthat is, the level of performance the subject actually expects to encounter. ${ }^{3}$ Evaluation of library services, including library instruction, has not conceptualized or measured satisfaction in this manner.

\section{Evaluating Library Instruction}

Various studies point to the need for library instruction for college students. A Johns Hopkins University study compared baseline measures of freshman library skills to upper-class students' skills, concluding that exposure to a library does not necessarily improve those skills nor do students learn good library skills on their own. ${ }^{4}$ This study also found students' self-assessment of library skills to be "quite accurate." Most studies agreed that some method of formal instruction is important. Evaluation usually focused on the efficacy of instruction or the supe- 
riority of one method over others. Evaluation criteria have been relatively narrowly focused; some were objective, some were subjective, and some were both. Although some looked at student satisfaction with the instruction sessions or programs, none focused on the relationship between instruction and the library service as a whole.

\section{Evaluation Using Objective Measures}

Numerous studies have used objective measures of student knowledge and skill performance to evaluate library instruction. These studies focused on the degree to which students' testable knowledge increased or performance improved following instruction. The usual objective of such studies was to assess whether the instruction subject matter was being learned by the students (i.e., whether the short-term goals of instruction were being met). Numerous variables and methods were used. One method was to examine the effects of instruction on patterns of library use. In their study of undergraduates at the University of Illinois, David N. King and John C. Ory found that instructed students used a wider variety of sources, made greater use of catalogs, and showed more use of various libraries and services. ${ }^{5}$ Evaluation of the library instruction program at the Ohio State University showed that instruction produced significant improvements in students' tested library knowledge and use. ${ }^{6}$ In a common approach to evaluating library instruction, Patricia Daragan and Gwendolyn Stevens used pre- and posttest measures to assess the library knowledge and skills of cadets at the U.S. Coast Guard Academy, and concluded that instruction increased students' levels of information literacy and narrowed the range of information literacy among incoming cadets. ${ }^{7}$

Some studies have compared different instructional methods and objectively evaluated their relative effectiveness. At Southeastern Oklahoma State University, four groups of students each received a different method of CD-ROM instruction, then used PsycLIT to complete test assignments that measured searching skills. ${ }^{8}$ Patricia F. Vander Meer and Galen E. Rike studied the effectiveness of a new multimedia self-instructional tutorial compared with the traditional method (a workbook and librarian introduction) and found higher posttest scores for both groups, but no significant differences in effectiveness. ${ }^{9}$

\section{Although some looked at student satisfaction with the instruction sessions or programs, none focused on the relationship between instruc- tion and the library service as a whole.}

Some studies combined objective approaches. For example, Trudi E. Jacobson and Janice G. Newkirk used questionnaires and examined printouts of search strategies to measure the impact of librarian instruction and assistance on students' CD-ROM search proficiency. ${ }^{10}$ They found some evidence that instruction or assistance had a positive effect on CDROM searching skill level, and a majority of students also reported that their search results were "valuable," which the authors referred to as "high satisfaction level."

\section{Evaluation Using Subjective Measures}

Effects of instruction on measurable skills or knowledge has not been the only focus of studies; many studies also have evaluated subjective factors such as students' comfort level in the library or confidence in their library skills. In addition, several studies addressed the degree to which student attitudes toward, and perceptions of, the library have changed following library instruction and/or whether the students were satisfied with instruction. The usual objective of such studies was to determine patron shortterm response specifically to the instruc- 
tion. The focus on subjective evaluations of library instruction presumably is the result of a growing recognition among librarians that "evaluation of library service quality is based on customer perception." ${ }^{11}$ Jacobson and Newkirk acknowledged that whether or not instruction produces increases in skills, "if students learn little but become comfortable with CD-ROM technology or with the library in general, our work is clearly purposeful." 12

A study at Southern Illinois University evaluated student "appreciation" of (i.e., "satisfaction" with) a full-term, one-credit course of bibliographic instruction, suggesting that the course produced a higher comfort level and confidence in library skills among upper-class students. ${ }^{13}$ Penelope Pearson and Virginia Tiefel used subjective questions to measure changes in attitudes toward and use of libraries among Ohio State University (OSU) students, and an independent OSU poll concurred with the library's conclusion that positive increases were related to the library instruction program. ${ }^{14}$ Subsequent evaluation confirmed that the OSU library instruction program improved student attitudes toward librarians and library services. ${ }^{15}$ Evaluation of a freshman library instruction program at North Park University suggested that students' confidence in their library skills and usefulness of the instruction increased with the program's new focus on learning styles. ${ }^{16}$ Researchers at Illinois State University used student "user panels" to evaluate integrated library instruction and discovered that the library instruction program may not be producing significant effects on students in the general education gateway course. ${ }^{17}$

\section{Evaluation Combining Both Objective and Subjective Measures}

In addition to the Johns Hopkins study cited earlier, ${ }^{18}$ many studies have used a combination of objective and subjective measures to evaluate instruction. Al- though some may see these two perspectives and their associated methodologies as being at least somewhat at odds, it is important to recognize that each perspective can contribute to the evaluation and ultimate improvement of library instruction as well as other programs.

King and Ory also looked at changes in student perceptions, which indicated that library instruction increased students' sense of confidence and competence in their use of the library. ${ }^{19}$ A study of library literacy of undergraduate students at the University of Northern Colorado (UNC) found that students' confidence levels increased with increased exposure to the library and its services (i.e., from freshman to senior years), although tested overall proficiency did not increase significantly. However, only seven percent of UNC students believed that bibliographic instruction was the primary influence in their development of library skills. ${ }^{20}$

At the University of Idaho, researchers found that library instruction can increase student knowledge as well as confidence level, regardless of teaching method or student personality type. ${ }^{21}$ Connie J. Ury and Terry L. King supplemented objective questionnaire data with data from focus groups that discovered significant agreement between student and faculty perceptions of library instruction activities. ${ }^{22}$ Vander Meer and Rike used attitudinal questions on the posttest portion of their questionnaires and found no significant differences between student ratings of the traditional and new instruction methods. ${ }^{23}$

\section{Service Quality versus Satisfaction in Library Evaluation}

Recent attempts to evaluate overall library performance from the patrons' perspective have focused on measuring service quality rather than satisfaction. These researchers used SERVQUAL, or a modified version of it, as an assessment instrument. ${ }^{24}$ This approach has greatly 
improved the quality of this type of research by (1) basing assessment on a model that is associated with relevant theory and (2) using an instrument that has itself been assessed for validity and reliability. The authors believe that the use of SERVQUAL has contributed significantly to the development of a theoretically and methodologically rigorous approach to library research.

Despite these strengths associated with the use of SERVQUAL, numerous limitations exist. First, SERVQUAL was developed within the context of five industries, which were neither libraries nor not-forprofit organizations. It was developed from excellent research conducted in the following five service sectors: product repair and maintenance, retail banking, long-distance telephone service, securities brokering, and credit cards. Although SERVQUAL may be considered a good starting place for evaluating generic forprofit service organizations, without significant additional research and revision it is unlikely that it would perform extremely well in evaluating the quality of library service.

Second, SERVQUAL items administered in actual service settings have consistently been shown to yield a factor structure inconsistent with that on which the instrument is based. In other words, researchers have found that the five service dimensions of SERVQUAL (reliability, responsiveness, assurance, empathy, and tangibles) rarely are replicated in a particular service organization context, including library contexts.

Third, the overall service quality rating derived from SERVQUAL appears to be not as highly correlated with general measures of service quality (from a user's perspective) as one should expect. In a recent review of literature reporting on SERVQUAL's use in library evaluation, Danuta A. Nitecki found correlations between an overall quality measure and an overall SERVQUAL score in the range of .58 to $.80 .{ }^{25}$ The average correlation was
.71. In practical terms, this means that about 50 percent of the variance in users' own perceptions of library service quality is accounted for by the SERVQUAL instrument. The remaining 50 percent of the variance is unexplained within the structure of SERVQUAL. If SERVQUAL really measured overall service quality from the users' perspective, one would expect a much higher correlation.

\section{Methodology}

This study focuses on the relationship between a specific service, library instruction, and user satisfaction with the library. Specifically, recognizing the key role of expectations in satisfaction formation, the authors evaluated the change in student expectations following library instruction and then examined how changes in expectations were related to overall satisfaction with the library.

Students in several sections of an introductory English composition course at a large, urban university were used as subjects for this study during the fall semester. The students were required to complete a library research project by the end of the semester. Library instruction sessions were held in each section of the course during the third week of class. The sessions used an approach that combined lecture and demonstration with a handson workshop and were geared to use active learning to teach students basic skills and concepts of library research. Students were taught basic techniques of using indexes and abstracts, searching CD-ROM databases, and using the library's online catalog. They worked in teams to research assigned topics chosen by English composition faculty. Class discussion followed the hands-on portion of the sessions.

The authors collected data at three times during the semester: during the week preceding the library instruction (T1), during the week immediately following the library instruction (T2), and during the week the research assignment was due, near the end of the semester (T3). 
The questionnaires were developed and pretested extensively in the six months preceding fieldwork and subsequently revised. In addition to the formal pretesting process, the authors solicited feedback from other members of the library staff. ${ }^{26}$

The T1 questionnaire contained questions about the students' expectations of the library collection, library staff, and computer- and print-based information; their confidence level regarding library use; and basic demographic information. The T2 questionnaire differed from the T1 questionnaire only in that demographic information was not solicited; that is, the T2 questionnaire focused on patron expectations and perceptions. The T3 questionnaire asked about actual experiences and perceptions of library performance; in addition, it asked students to indicate their overall level of satisfaction with the library. Completed questionnaires were collected and matched for seventy-six individuals; that is, seventy-six students completed each of the three questionnaires.

Analysis focused on addressing the following three questions:

1. Which perceptions of performance are most/least associated with patron satisfaction?

2. Which perceptions of performance are or are not congruent with $\mathrm{T} 2$ expectations?

3. Which $\mathrm{T} 2$ expectations appear to have been influenced by the library instruction?

It is important to avoid falling into the trap of using only library instruction-related variables to assess user satisfaction. Studies that only consider program-specific variables as antecedents of satisfaction nearly always will find relationships between the program and satisfaction because the analytical procedures only have the program-specific variables available to explain variance in satisfaction. By using program-specific variables and other reasonable measures (as developed during pretesting), the impact of the program rela- tive to other possible antecedents can be assessed. This information is more useful to administrators than is program-specific information presented in a vacuum.

\section{Findings}

Analysis of the data is based primarily on two established procedures: the paired $t-$ test difference of means test and correlation analysis. The former test is useful when measurements are taken of a particular group of individuals at different points in time; it is appropriate for determining whether there is any difference (1) in the mean value of a single variable measured at two different times or (2) between two different variables when the variables can be matched to a specific individual. Correlations simply reflect the strength of the linear relationship between two variables and range from -1.0 to 1.0. Positive correlations indicate a positive relationship, negative correlations reflect an inverse relationship, and a correlation of 0.0 indicates the two variables are unrelated.

Table 1 lists selected study variables in column 1. Column 2 contains the difference of means in expectations/assessments before (T1) and after (T2) the library instruction. Positive numbers indicate the degree to which average values for that variable increased following instruction, and negative numbers indicate the degree to which average values decreased following instruction. In column 3 , the difference between perceived performance (T3) and post-instruction expectations / assessments (T2) are presented. The asterisks by a number in columns 2 and 3 indicate that the difference is statistically significant. Column 4 contains the simple correlations between performance and overall satisfaction with the library. The asterisks in this column indicate those correlations that are statistically significant. Positive numbers indicate a positive relationship between performance and overall satisfaction, and negative numbers indicate a negative relationship. 


\begin{tabular}{|c|c|c|c|}
\hline \multicolumn{4}{|c|}{$\begin{array}{c}\text { TABLE } 1 \\
\text { Results }(N=76) \\
\end{array}$} \\
\hline $\begin{array}{r}\text { Pre-i } \\
\text { Post-in }\end{array}$ & $\begin{array}{l}\text { hange in } \\
\text { nstruction to } \\
\text { struction Values } \\
\text { T2 - T1) }\end{array}$ & $\begin{array}{l}\text { Difference between } \\
\text { Performance and } \\
\text { Expectations } \\
(\mathrm{T} 3-\mathrm{T} 2)\end{array}$ & $\begin{array}{c}\text { Correlation between } \\
\text { Performance and } \\
\text { Satisfaction }\end{array}$ \\
\hline \multicolumn{4}{|c|}{ General Library } \\
\hline $\begin{array}{l}\text { Percent of needed materials } \\
\text { available at the library }\end{array}$ & 2.014 & -4.045 & $.53 * * *$ \\
\hline Rarely has the material I need & 0.030 & -0.075 & $-.66^{* * *}$ \\
\hline Difficult to find materials at & -0.074 & $-0.269 * *$ & $-.41 * * *$ \\
\hline \multicolumn{4}{|c|}{ Library Specifics } \\
\hline Average wait time for books & $0.313^{* *}$ & $-1.183 * * *$ & -.07 \\
\hline Maximum wait time for books & $0.194 *$ & $-1.759 * * *$ & -.08 \\
\hline Average wait time for articles & $0.388 * * *$ & $-0.906 * * *$ & -.09 \\
\hline Maximum wait time for articles & 0.134 & $-1.328 * * *$ & $-.24 *$ \\
\hline Computers useful for research & 0.000 & 0.090 & $.40 * * *$ \\
\hline Computers difficult to use & -0.149 & -0.209 & $-.49 * * *$ \\
\hline $\begin{array}{l}\text { Printed references useful for } \\
\text { research }\end{array}$ & -0.119 & -0.090 & .16 \\
\hline Printed references difficult to use & 0.045 & 0.060 & -.19 \\
\hline \multicolumn{4}{|c|}{ Library Staff } \\
\hline Library staff competent & -0.224 & 0.045 & $.47 * * *$ \\
\hline Library staff helpful & -0.030 & $-0.448 * * *$ & $.58 * * *$ \\
\hline \multicolumn{4}{|c|}{ Patron Self-Assessment } \\
\hline Skillful using libraries in general & $0.164^{*}$ & $0.149 *$ & $.21 *$ \\
\hline Skillful using the university library & $0.433 * * *$ & $0.239 * *$ & $.32 * * *$ \\
\hline $\begin{array}{l}\text { Hours spent conducting } \\
\text { library research }\end{array}$ & 0.149 & $-0.462 * * *$ & .05 \\
\hline $\begin{array}{l}\text { Levels of significance } \\
* \mathrm{p}<.10 \quad * * \mathrm{p}<.05 * * * \mathrm{p}<.01\end{array}$ & & & \\
\hline
\end{tabular}

\section{Difference between Pre- and Post- Instruction Values}

Looking at the results in column 2, significant differences appear in only two general categories:

1. Wait time for materials: Patron estimates of average wait times for books and articles and the expected maximum wait time for books increased significantly following library instruction.

2. Self-assessed skill level: Patrons assessed their skill level as being higher fol- lowing library instruction.

Somewhat surprisingly, there were no significant differences in expectations regarding the usefulness or difficulty in using computers or print references, in the general availability of material at the library, or in the expected helpfulness / competence of the library staff.

Difference between Performance and Postinstruction Expectations

Looking at column 3, assessed perfor- 
mance differed from patron expectations in five areas:

1. Perceptions of the difficulty of finding material in the library: Patrons experienced less difficulty in finding material than expected.

2. Wait time for articles and books: Patrons received materials faster than expected; average and maximum wait times were shorter than expected for both books and articles.

3. Perceptions of staff helpfulness: Patrons perceived the library staff to be significantly less helpful than expected.

4. Self-assessed skill level: Patrons assessed their skill level as being significantly higher at T3 than they did at T2.

5. Hours spent conducting library research: Patrons spent significantly less time conducting library research than expected.

\section{Correlates of Satisfaction}

Finally, looking at column 4, performance in four general areas appears to be correlated with satisfaction:

1. Perceptions of information accessibility: The proportion of needed materials available at the library, the difficulty of finding the materials, and the maximum wait time for articles all are significantly related to overall satisfaction with the library.

2. Perceptions of staff competence and helpfulness: Perceptions that library staff are competent and helpful are highly correlated with overall satisfaction.

3. Perceptions of computers: There is a moderate positive relationship between the perceived usefulness of library computers and overall satisfaction, and a moderate negative relationship between the perceived difficulty of using computers and overall satisfaction.

4. Self-assessment of skill for using the library: There is a moderate positive correlation between a person's self-assessed skill level for using libraries and overall satisfaction with the library.

Surprisingly, performance in three other areas appears not to be related to satisfaction:
1. perceived wait time for books;

2. perceived usefulness or perceived difficulty of using print references;

3. time spent in the library conducting library research.

\section{Discussion}

The primary objectives of library instruction sessions focused on students learning basic skills needed to complete their assignments. Closely tied to these were the objectives that students would gain realistic expectations of library resources and learn that library staff are available and willing to help. Librarians might expect that after an introductory session covering various sources and search techniques, most students would have different expectations of the library and more favorable perceptions of library staff. Student expectations about the amount of time it takes to obtain library materials increased following instruction and, it is hoped, moved closer to the level at which the library usually performs. Student perceptions of their skill levels also increased, consistent with previous studies that suggested library instruction can increase student confidence levels.

However, some results were not so straightforward. Instruction did not appear to affect student expectations of computers or print sources. Students knew that a main purpose of the sessions was to learn practical computer-centered library skills, which would benefit them in the class. Many of the students had previous experience with computers and probably were predisposed to positive attitudes and expectations about them. It may be that these students already had positive perceptions of computers in general, which they applied to library computer systems as well. The library context of the computers may not have affected students' already high views of computer usefulness. It also is surprising that expectations about difficulty using computers did not change significantly. It seems reasonable that hands-on expe- 
rience would either raise or lower expectations, and librarians assume or hope that comfort and ease of use come with practice. The English composition teachers focused more on journal sources than books or other formats, and much of the librarians' instruction involved searching of indexes and abstracts via computer. It is possible that print sources may have been taken for granted by, or considered irrelevant by, the students in this sample.

Another implied objective of library instruction was to increase student expectations concerning the availability of appropriate materials to meet their research needs. It is unclear whether instruction was unsuccessful in this or whether expectations were already high and difficult to move up. It also might be expected that following library instruction, students would have greater expectations of helpfulness and competence of library staff. However, this was not the case, and it is unclear why students' experience with librarian instructors did not inspire more confidence in library staff. Does this reflect a student perception of less-thanadequate performances on the part of librarian instructors? Does student assessment of library staff decrease as self-assessment of skills increases? Are students, in effect, comparing library staff competence and helpfulness to their own perceived abilities and seeing themselves as closer in knowledge and skills to library staff? These are questions that might be addressed in further research.

In the third wave of the survey, students assessed their own performance, as well as that of the library and its staff. Not only did students find it easier to use the library than they had expected, but it did not take as long to receive needed materials as they had believed it would. In the students' experience, the library performed better in these areas. Students found the library staff to be less helpful than expected. It is difficult to know what this means, particularly because the library experiences of students exposed them to a much wider range of personnel than the librarian instructor in the instruction session. Moreover, it is unclear what students judged to be helpful or not helpful behaviors or perceived attitudes of staff.

If students really found themselves using the library faster and more easily than they expected, perhaps they perceived less need for help from staff. Given student assumptions, library instruction librarians should not find it surprising that successful performance, along with increased exposure or experience, might

\section{Student expectations about the amount of time it takes to obtain library materials increased following instruction and, it is hoped, moved closer to the level at which the library usually performs.}

result in students' higher self-assessment of library skills. One might ask whether this is more a function of increased skills and knowledge or one of building selfconfidence. It would seem difficult to separate the two, especially because other studies have shown students to be relatively good judges of their library skills. Most likely, the finding that students spent less time doing their research than they expected is an extension of the performance-related findings stated above.

These findings suggest that certain factors in students' library experience, such as access to information and perceptions of library staff, are considerably more important to their overall satisfaction than are other factors. Accessibility is valued by students, and the more accessible materials were, the more satisfied the users were. Similarly, students valued library staff, and when they perceived staff to be competent and helpful, they were more satisfied with the library as a whole.

It is interesting that the perceived usefulness and ease of use of computers as a reference source are associated with patron satisfaction, but perceived usefulness 
and ease of using print reference sources are not. The university library at which this research was conducted is a leader in the use of computers in a university library setting. PC and Macintosh workstations with full Internet and multiple database access are widely available throughout the library. It is unclear from this research whether the importance of computer-based reference material was correlated with patron satisfaction because computers were the only reference source used or because a different structural relationship exists between computer use and patron satisfaction versus print reference use and patron satisfac-

\section{For library skills in general, the better students feel their skills are, the more satisfied they will be with the library.}

tion. The library instruction sessions were all conducted in an electronic classroom, and English composition faculty promoted the importance of electronic databases, while in effect disregarding print sources. For a variety of reasons, students may have been predisposed to favor or place higher value on electronic information sources. Their hands-on experience in the instruction sessions was almost exclusively centered on electronic sources and searching for periodical citations. Even when they used the catalog, it was mostly to see if the library subscribed to particular journals. Handouts, with the exception of the catalog handout, also focused on journals.

For library skills in general, the better students feel their skills are, the more satisfied they will be with the library. The university is located on a busy, nontraditional, urban campus, where students place a high value on time and efficiency. It was surprising, therefore, to find that the time necessary to obtain books and conduct library research was not a factor in student satisfaction with the library.

It also is interesting to note that wait time for articles is only slightly correlated with satisfaction and that wait time for books is not correlated with patron satisfaction at all. This result is somewhat surprising because the literature has indicated that long waits are associated with dissatisfaction. However, the results of previous research and the results obtained in this study are not necessarily incongruous. It is possible that for some service aspects, a two-factor conceptualization is appropriate. Two-factor theory states that certain variables have the power only to dissatisfy people whereas others have the power only to satisfy. A dissatisfying factor has the power to dissatisfy patrons if performance is below some threshold level. However, after performance reaches the threshold, dissatisfaction disappears, but further improvements in the factor do not increase satisfaction. After the threshold levels of performance have been reached for all dissatisfying factors, satisfaction increases as performance on satisfying factors increases. ${ }^{27}$

Two-factor theory was originally developed to explain job satisfaction; there is some evidence that a two-factor conceptualization is relevant to consumer satisfaction situations as well. If two-factor theory is relevant in library services, it is possible that wait time perceived to be excessive may dissatisfy patrons, but wait times perceived as reasonable do not have the power to raise satisfaction ratings. If this is true, the measured effect of library instruction regarding wait timethat is, the observed effect of increasing expected wait time-may be seen as having a positive effect on satisfaction, not because satisfaction increases but, rather, because the library instruction may have prevented patrons from becoming dissatisfied. The relevance of two-factor theory to library services in general, and with regard to wait time in particular, is an area requiring additional research effort.

In summary, of the variables measured in this study, the only effects of instruction that are directly associated with 
longer-term patron satisfaction appear to be related to patron self-assessed skill levels. In this regard, the study findings are consistent with those of Pearson and Tiefel-increasing patrons' confidence in their skill at using libraries in itself has a positive impact on their perception of the library. One major opportunity uncovered during this project is that of improving patron perception about the library staff, especially with regard to helpfulness. Actual perceived helpfulness was significantly lower than expected, yet staff helpfulness is more strongly correlated with patron satisfaction than is any other single variable. Expectations of helpfulness did not change as a result of the instruction, which in retrospect probably is a good thing: If expectations had risen following the instruction, and perceived staff helpfulness remained unchanged, it is likely that overall satisfaction among this group would have been lower. The managerial implication is that either patron expectations of staff helpfulness ought to be lowered (a dangerous strategy) or perceptions of staff helpfulness ought to be raised.

\section{Conclusions}

Development of a comprehensive "drivers of satisfaction" model will have sig- nificant implications for assessment, accountability, and library administration. The explicit recognition that patron satisfaction is one component of library quality means that its measurement is a logical component of assessment. Libraries frequently assess individual aspects of library service-for example, reference, instruction, circulation, document delivery, collection development. In addition, they would be well served by looking at the degree to which such aspects, individually as well as collectively, contribute to overall satisfaction.

Within this framework, understanding what drives satisfaction at a specific library requires an ongoing measurement effort. It is unlikely that any two libraries will have the same "drivers" weighted in the same manner, so although the evaluation process described here may be generalizable, the specific findings probably are not. The first step is for each library to identify what variables are correlated with satisfaction and then to determine which activities under the control of the library staff influence those variables. The ultimate goal of such an effort is to understand and manage those activities that determine user satisfaction with the library.

\section{Notes}

1. Youjae Yi, "A Critical Review of Consumer Satisfaction," in Review of Marketing 1990, ed. Valarie A. Zeithaml (Chicago: American Marketing Association, 1990); Robert A. Peterson and William R. Wilson, "Measuring Customer Satisfaction: Fact and Artifact," Journal of the Academy of Marketing Science 20 (winter 1992): 61-71.

2. David K. Tse and Peter C. Wilton, "Models of Consumer Satisfaction Formation: An Extension," Journal of Marketing Research 25 (May 1988): 204-12; Richard A. Spreng, Scott B. MacKenzie, and Richard W. Olshavsky, "A Reexamination of the Determinants of Consumer Satisfaction," Journal of Marketing 60 (July 1996): 15-32.

3. Yi, "A Critical Review of Consumer Satisfaction"; Richard L. Oliver, "A Cognitive Model of the Antecedents and Consequences of Satisfaction Decisions," Journal of Marketing Research 17 (Nov. 1980): 460-69.

4. Jill Coupe, "Undergraduate Library Skills: Two Surveys at Johns Hopkins University," Research Strategies 11, no. 4 (fall 1993): 187-201.

5. David N. King and John C. Ory, "Effects of Library Instruction on Student Research: A Case Study," College E Research Libraries 42 (Jan. 1981): 31-41.

6. Virginia Tiefel, "Evaluating a Library User Education Program: A Decade of Experience," College $\mathcal{E}$ Research Libraries 50 (Mar. 1989): 249-59.

7. Patricia Daragan and Gwendolyn Stevens, "Developing Lifelong Learners: An Integrative and Developmental Approach to Information Literacy," Research Strategies 14, no. 2 (spring 
1996): 68-81.

8. Dorothy F. Davis, "A Comparison of Library Bibliographic Instruction Methods on CDROM Databases," Research Strategies 11, no. 3 (1993): 156-63.

9. Patricia F. Vander Meer and Galen E. Rike, "Multimedia: Meeting the Demand for User Education with a Self-Instructional Tutorial," Research Strategies 14, no. 3 (summer 1996): 145-58.

10. Trudi E. Jacobson and Janice G. Newkirk, "The Effect of CD-ROM Instruction on Search Operator Use," College \& Research Libraries 57 (Jan. 1996): 68-76.

11. Vicki Coleman, Yi Xiao, Linda Bair, and Bill Chollett, "Toward a TQM Paradigm: Using SERVQUAL to Measure Library Service Quality," College \& Research Libraries 58 (May 1997): 237.

12. Jacobson and Newkirk, "The Effect of CD-ROM Instruction on Search Operator Use," 76.

13. Roland Person, "Long-Term Evaluation of Library Bibliographic Instruction: Lasting Encouragement," College \& Research Libraries 42 (Jan. 1981): 19-25.

14. Penelope Pearson and Virginia Tiefel, "Evaluating Undergraduate Library Instruction at The Ohio State University," Journal of Academic Librarianship 7, no. 6 (Jan. 1982): 351-57.

15. Tiefel, "Evaluating a Library User Education Program."

16. Sonia Bodi, "Teaching Effectiveness and Library Bibliographic Instruction: The Relevance of Learning Styles," College E Research Libraries 51 (Mar. 1990): 113-19.

17. Carroll H. Varner, Vanette M. Schwartz, and Jessica George, "Library Instruction and Technology in a General Education 'Gateway' Course: The Student's View," Journal of Academic Librarianship 22, no. 5 (Sept. 1996): 355-59.

18. Coupe, "Undergraduate Library Skills."

19. King and Ory, "Effects of Library Instruction on Student Research."

20. Arlene Greer, Lee Weston, and Mary Alm, "Assessment of Learning Outcomes: A Measure of Progress in Library Literacy," College \& Research Libraries 52 (Nov. 1991): 549-57.

21. Diane Prorak, Tania Gottschalk, and Mike Pollastro, "Teaching Method and Psychological Type in Library Bibliographic Instruction: Effect on Student Learning and Confidence," RQ 33, no. 4 (summer 1994): 484-95.

22. Connie J. Ury and Terry L. King, "Reinforcement of Library Orientation Instruction for Freshman Seminar Students," Research Strategies 13, no. 3 (summer 1995): 153-64.

23. Vander Meer and Rike, "Multimedia."

24. Danuta A. Nitecki, "Changing the Concept and Measure of Service Quality in Academic Libraries," Journal of Academic Librarianship 22, no. 3 (May 1996): 181-90; Coleman, Xiao, Bair, and Chollett, "Toward a TQM Paradigm," 237-51.

25. Danuta A. Nitecki, "Assessment of Service Quality in Academic Libraries: Focus on the Applicability of the SERVQUAL," in Proceedings of the $2^{\text {nd }}$ Northumbria International Conference on Performance Measurement in Libraries and Information Services, September 7-11, 1997 (Newcastle upon Tyne: Information North for the Department of Information and Library Management, University of Northumbria at Newcastle, 1998), 181-96.

26. Questions are available from the authors.

27. F. Herzberg, B. Mausner, and B. Snyderman, The Motivation to Work, 2nd ed. (New York: Wiley, 1959). 